\title{
Epithelioid leiomyosarcoma: a rare uterine cancer
}

\author{
Upadhya Rekha*, Vidyashree G. Poojari, Muralidhar V. Pai, Jayaraman Nambiar
}

Department of Obstetrics and Gynecology, Kasturba Medical College, MAHE, Karnataka, India

Received: 10 February 2018

Accepted: 07 March 2018

\author{
*Correspondence: \\ Dr. Upadhya Rekha, \\ E-mail: rex2000@rediffmail.com
}

Copyright: (C) the author(s), publisher and licensee Medip Academy. This is an open-access article distributed under the terms of the Creative Commons Attribution Non-Commercial License, which permits unrestricted non-commercial use, distribution, and reproduction in any medium, provided the original work is properly cited.

\begin{abstract}
A uterine epithelioid leiomyosarcoma is a rare malignant tumour that arises from the smooth muscle lining the walls of the uterus. The exact cause of leiomyosarcoma, including uterine leiomyosarcoma accounting for 5 to $10 \%$ is unknown. Leiomyosarcoma is the most common subtype of uterine sarcoma, accounts for 1-2\% of uterine malignancies. Malignancy should be suspected in menopausal women with tumour growth who are not on hormonal replacement therapy. A 64-year-old female had attained menopause 16 year back and developed postmenopausal bleeding since 2 months, with palpable mass, of 16 weeks size. Ultrasonography showed whorled mass lesions, endometrium and myometrium could not be seen separately. Uterus with both ovaries removed. Intra-operative findings showed 16 weeks uterine mass with size $15 \times 10.5 \times 10 \mathrm{~cm}$ and weight $1 \mathrm{~kg}$ with intramural fibroid. Necrotic and haemorrhagic areas with degenerative changes seen on cut section suggestive of malignancy. Histopathology and immunohistochemistry reported epithelioid leiomyosarcoma.
\end{abstract}

Keywords: Epithelioid, Immunohistochemistry, Leiomyosarcoma, Postmenopause

\section{INTRODUCTION}

Leiomyosarcoma is a relatively rare form of cancer, comprising between 5 and $10 \%$ of soft tissue sarcomas, which are in themselves relatively rare. ${ }^{1,2}$ Leiomyosarcomas can be very unpredictable. This tumour may recur after many ears. It is a chemo/radio resistant cancer. The best outcomes occur when it can be removed surgical with wide margins early, while small and still in situ. Uterine epithelioid leiomyosarcoma is a rare smooth muscle neoplasm. It is distinguished on cytoarchitectural grounds from the majority of leiomyosarcomas that arise in the uterus. ${ }^{3}$ After excluding carcinosarcoma, leiomyosarcoma has become the most common subtype of uterine sarcoma. It accounts for only $1-2 \%$ of uterine malignancies. Most occur in women over 40 years of age who usually present with abnormal vaginal bleeding (56\%), palpable pelvic mass (54\%) and pelvic pain $(22 \%) .{ }^{4}$ Signs and symptoms resemble those of the far more common leiomyoma and preoperative distinction between the two tumours may be difficult. Malignancy should be suspected by the presence of certain clinical behaviours, such as tumour growth in menopausal women who are not on hormonal replacement therapy. ${ }^{5}$ Occasionally, the presenting manifestations are related to tumour rupture (hemoperitoneum), extra-uterine extension (one-third to one-half of cases), or metastases. leiomyosarcoma originating from a leiomyoma is rare. Author are reporting a case of uterine epithelioid leiomyosarcoma.

\section{CASE REPORT}

P2L2 with two previous LSCS admitted with h/o postmenopausal bleeding for one week and generalized weakness. She had menopause 16 years back. Scan done 
in the month of June 2017 showed bulky uterus with distorted endometrium and myometrium with large iso to hypo echoic lesion of $2-5 \mathrm{~cm}$ within the parenchyma. Features suggestive of diffuse adenomyosis/malignancy. Histopathology of cervical polyp showed chronic inflammatory endocervical polyp. She was referred here for further evaluation. Blood group $(\mathrm{O}+\mathrm{ve}), \mathrm{Hb}$ $(10.8 \mathrm{gm} \%)$, TSH, liver and renal function tests were normal. Endometrial sampling done here showed Endometroid adenocarcinoma grade 3 stage 1b. Scan showed intrauterine growth seen in uterine cavity measuring $6.9 \mathrm{~cm}$ with multiple fibroids. Endometrial thickness was indistinct.

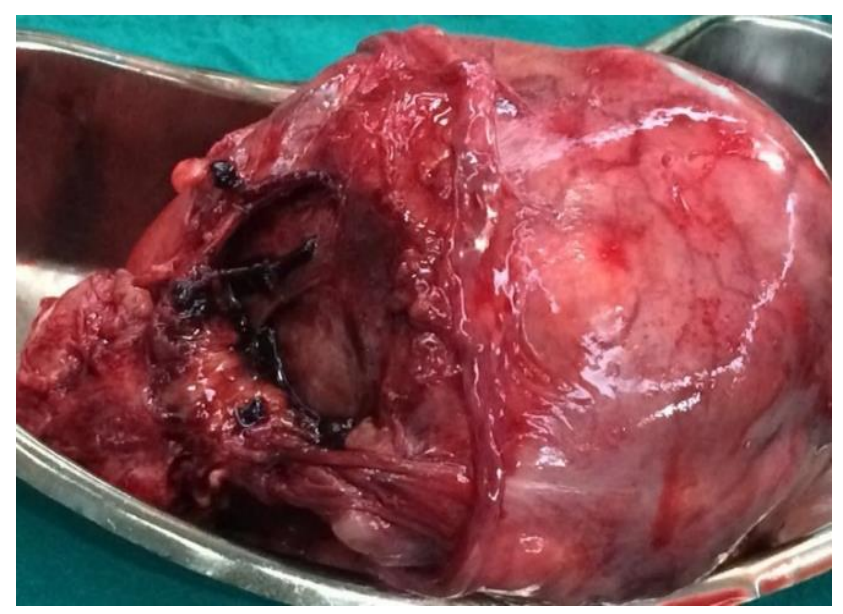

Figure 1: Gross appearance.

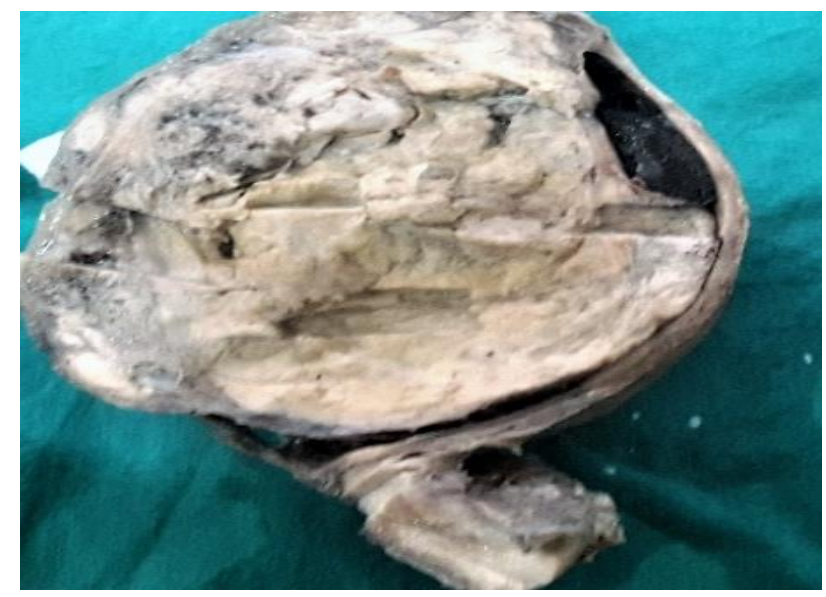

Figure 2: Cut section showing black and yellow necrotic and haemorrhagic areas with degenerative changes suggestive of malignancy.

\section{Treatment}

Total abdominal hysterectomy with bilateral salpingoophorectomy was performed under general anesthesia. Intraoperative findings showed 16 weeks uterine mass with size $15 \times 10.5 \times 10 \mathrm{~cm}$ and weight $1 \mathrm{~kg}$ with intramural fibroid (Figure 1). Cut section of removed specimen showed black and yellow necrotic and hemorrhagic areas with degenerative changes suggestive of malignancy (Figure 2).

There were no palpable secondaries or lymphadenopathy. Postoperatively she received one unit of blood transfusion and injectable antibiotics (third generation cephalosporins and tinidazole) for 5 days. Postoperative period was uneventful. In view of histopathology report showing endometroid adenocarcinoma grade 3 stage $1 \mathrm{~b}$ advised EBRT followed by VBT as per Radiotherapy consultation. She was discharged home on postoperative day 10. Gross morphology showed large solitary or dominant mass in the uterus of around $10 \mathrm{~cm}$. Soft, bulging, fleshy, gray to cream color with variable haemorrhage and necrosis and irregular margins. Tumor cells arranged diffusely in nests and cords. Moderate to severe atypia with increased mitotic areas /10 high power fields, necrotic areas and infiltrative margins fulfilling the diagnostic criteria. Further confirmation done based on immunohistochemistry which showed SMA, vimentin and keratin positive.

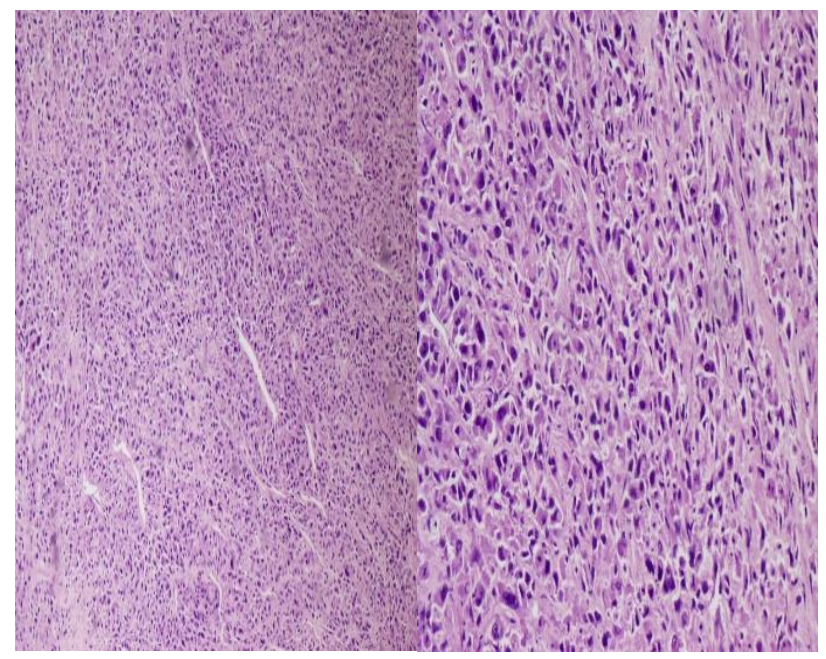

Figure 3: Solid sheets of malignant cells with pleomorphic round to oval hyperchromatic nuclei, coarse chromatin, prominent nucleoli and abundant eosinophilic cytoplasm.

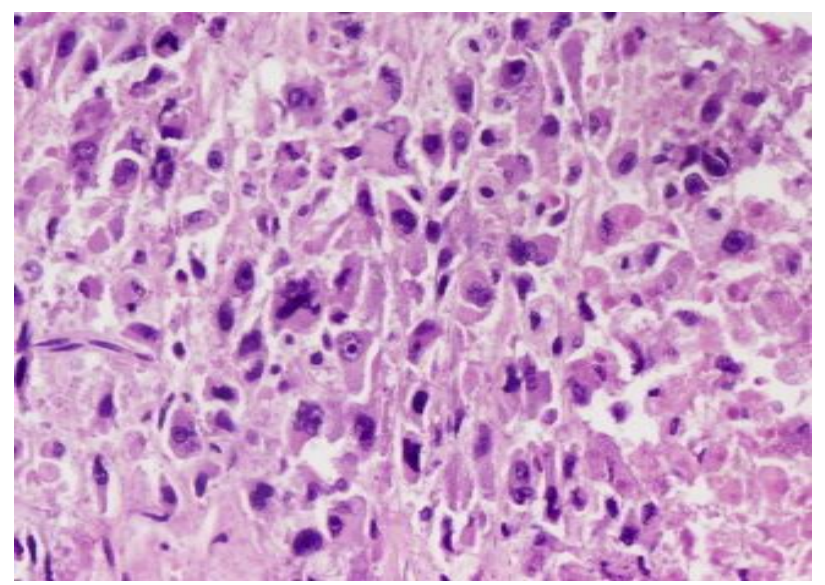

Figure 4: Tumor with increased mitotic. 


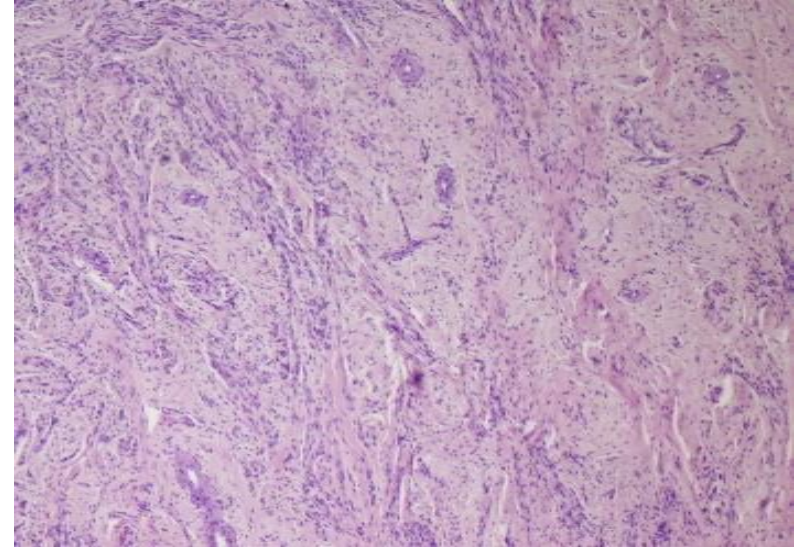

Figure 5: Tumor cells arranged in whorl or storiform pattern.

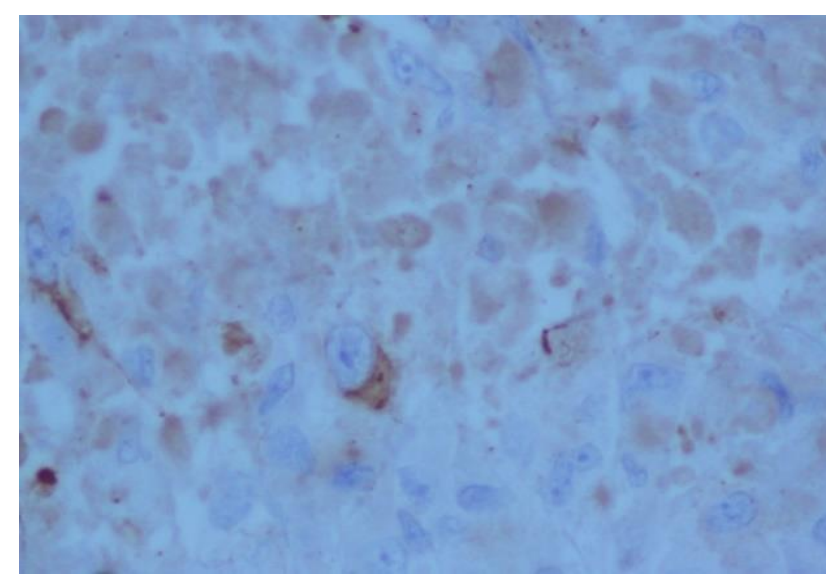

Figure 6: EMA focally positive.

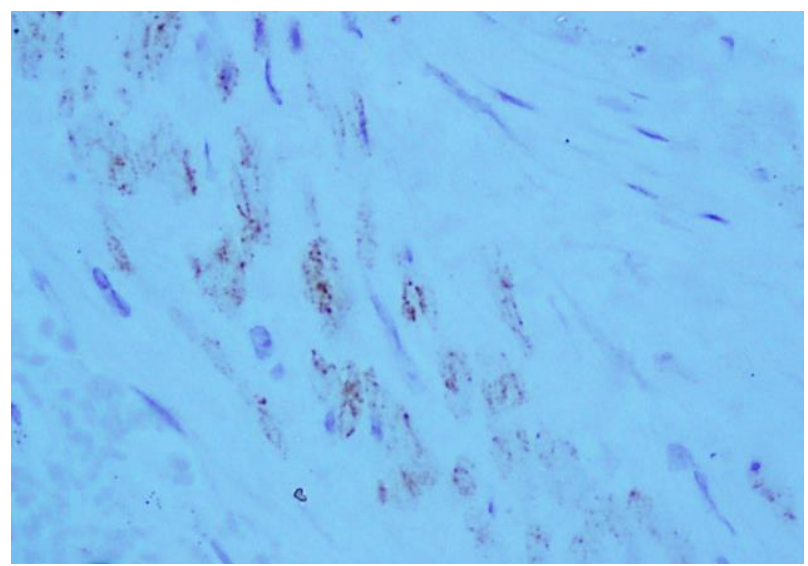

Figure 7: Pan Cytokeratin Strong positive in focal tumor cells.

\section{Follow-up}

She reported after one week with vomiting, surgical consultation was sought, conservatively treated as CECT suggested possibility of subacute intestinal obstruction due to adhesions. Patient recovered on conservative management. Radiotherapy was deferred due to poor prognosis. she is currently asymptomatic. Advised follow-up.

\section{DISCUSSION}

Uterine leiomyosarcoma (ULMS) are known to be aggressive as compared with the other endometrial carcinomas and associated with a poor prognosis. ULMS tumours account for $1 \%$ of patients with uterine cancer. Incidence of 0.64 per 100000 women. ${ }^{6,7}$ ULMS are of high metastatic tumours with 5-year survival rates from 0 and $73 \%{ }^{8,9}$ ULMS occur commonly in women 40 to 60 years of age group. The frequent presenting symptoms are abnormal vaginal bleeding and pelvic or abdominal pain. The patients may present with spotting to menorrhagia and foul-smelling vaginal discharge. Weight loss, weakness, lethargy and fever are less common symptoms. The uterus is often enlarged, and part of the tumour may prolapse through the cervix and vaginal canal. Diagnosis is difficult before surgery, because of this patient present with advanced disease. there are inconclusive data on onset of menarche, or age at menopause as risk factors. Uterine leiomyosarcoma is a rare cancer that affects as few as seven adult women in a million. The 5-year survival rates for women who are diagnosed in Stage I of the disease is around 50 to 65 per cent. ${ }^{10,11}$ If the disease is more advanced at the time of diagnosis, the5-year survival rate for uterine leiomyosarcoma drops to 0 to 20 percent. The poor prognosis is largely due to two factors, the high incidence of recurrence and the ease with which the disease can spread to other organs of the body through the blood and lymphatic systems.

The histopathologic diagnosis of uterine leiomyosarcoma is usually straight forward since most clinically malignant smooth muscle tumours of the uterus show the microscopic constellation of hyper cellularity, severe nuclear atypia, and high mitotic rate generally exceeding 15 mitotic figures per 10 high-power fields (MF/10 HPF). ${ }^{12,13}$ Finally, mitotic count was also a significant factor in the subset of 97 stage I uterine LMSs, along with period and menopausal status in the study by Larson et al. One or more clinicopathologic features such as perior postmenopausal age, extra uterine extension, more than $10 \mathrm{~cm}$ tumours, infiltrating border, necrosis and atypical mitotic figures are usually present. Recognising Epithelioid and myxoid leiomyosarcomas, may be difficult microscopically as their pathologic features differ from those of ordinary spindle cell leiomyosarcomas. Nuclear atypia is mild in both tumour types with mitotic rate $3 \mathrm{MF} / 10 \mathrm{HPF}$. Necrosis may be absent in epithelioid variety and myxoid leiomyosarcomas are often hypo cellular. In the absence of severe cytologic atypia and high mitotic activity, both tumours are diagnosed as sarcomas based on their infiltrative borders. ${ }^{14}$ The minimal pathological criteria for the diagnosis of leiomyosarcoma are more problematic and, in such cases, the differential diagnosis has to be made, not only with a variety of benign smooth 
muscle tumours that exhibit atypical histologic features and unusual growth patterns. Very few cases are reported in the literature. Similar studies have been reported by Toyoshima et al whereby they observed a massive vaginal bleeding from a cervical tumour in a Japanese woman. ${ }^{15}$ Total hysterectomy with bilateral salpingooophorectomy done in these patients. Histological findings suggestive of epithelioid leiomyosarcoma of the cervix. The patient underwent adjuvant chemotherapy and has been disease-free for over 20 months. Wang et al recently reported clinical pathological parameters such as tumour cell necrosis and lymphovascular invasion as the presenting symptom of epithelioid leiomyosarcoma and reviewed 27 cases (17 spindled, 5 epithelioid, 2 myxoid and 3 mixed) of leiomyosarcomas. ${ }^{16}$ The best chance for a cure is an isolated LMS tumour that was surgically excised with wide, clear margins, while it was small. Even some of these patients have recurrences or metastases, though the 'still clear' rate may be as high as 80 or $90 \%$ at 5 years. High-grade with large size tumour have more chance of recurrence or metastasis. The recurrence rate or metastasis is as high as $80 \%$ or more. The chemotherapeutic agent like Doxorubicin, is not that successful. Partial success rate seen in $30 \%$ patients. A very few may go into what looks like complete remission. The rest will not respond to doxorubicin. And the response does not last that long (months).

\section{ACKNOWLEDGMENTS}

Authors would like to thank Dr. Kantilatha Pai for his support during study.

Funding: No funding sources Conflict of interest: None declared

Ethical approval: Not required

\section{REFERENCES}

1. Norris HJ, Zaloudek CJ. Mesenchymal tumors of the uterus. In: Blaustein A. Pathology of the Female Genital Tract. $2^{\text {nd }}$ Ed. New York: Springer; 1982:352.

2. Weaver MJ, Abraham JA. Leiomyosarcoma of the bone and soft tissue: a review. Electronic sarcoma update newsletter. 2007;4.

3. Buscema J, Carpenter SE, Rosenshein NB. Epithelioid leiomyosarcoma of the uterus. Cancer. 1986;57:1192-6.

4. D'Angelo E, Prat J. Uterine sarcomas: a review. Gynecol Oncol. 2010;116:131-9.
5. Perri T, Korach J, Sadetzki S. Uterine leiomyosarcoma: does the primary surgical procedure matter?. Int $\mathrm{J}$ Gynecol Cancer. 2009; 19:257-60.

6. Harlow BL, Weiss NS, Lofton S. The epidemiology of sarcomas of the uterus. J Natl Cancer Inst. 1986;76:399-402.

7. Bartsich EG, Bowe ET, Moore JG . Leiomyosarcoma of the uterus. A 50-year review of 42 cases. Obstet Gynecol. 1968;32:101-6.

8. Kurman RJ, Norris HJ. Mesenchymal tumors of the uterus. VI. Epithelioid smooth muscle tumors including leiomyoblastoma and clear-cell leiomyoma: a clinical and pathologic analysis of 26 cases. Cancer. 1976;37:1853-65.

9. Appleman HD, Helwig EB. Gastric epithelioid leiomyoma and leiomyosarcoma (leiomyoblastoma). Cancer. 1976;38:708-28.

10. Livi L, Paiar F, Shah N. Uterine sarcoma: twentyseven years of experience. Int J Radiat Oncol Biol Phys. 2003;57:1366-73.

11. Major FJ, Blessing JA, Silverberg SG. Prognostic factors in early-stage uterine sarcoma. A Gynecologic Oncology Group study. Cancer. 1993;71:1702-9.

12. Zaloudek CJ, Norris HJ . Mesenchymal tumors of the uterus . In: Fenoglio CM, Wolff M, eds. Progress in Surgical Pathology. New York: Masson; 1981;3:135.

13. Evans HL, Chawla SP, Simpson C. Smooth muscle neoplasms of the uterus other than ordinary leiomyoma. A study of 46 cases, with emphasis on diagnostic criteria and prognostic factors. Cancer. 1988;62:2239-47.

14. Atkins K, Bell S, Kempson M. Myxoid smooth muscle tumors of the uterus. Modern Pathol. 2001;14:132A.

15. Toyoshima M, Okamura C, Niikura H. Epithelioid leiomyosarcoma of the uterine cervix: a case report and review of the literature. Gynecol Oncol. 2005;97:957-60.

16. Wang WL, Soslow R, Hensley M. Histopathologic prognostic factors in stage I leiomyosarcoma of the uterus: a detailed analysis of 27 cases. Am J Surg Pathol. 2011;35:522-9.

Cite this article as: Rekha U, Poojari VG, Pai MV, Nambiar J. Epithelioid leiomyosarcoma: a rare uterine cancer. Int J Reprod Contracept Obstet Gynecol 2018;7:1663-66. 